\title{
Percepção de familiares referente ao banho humanizado: técnica japonesa em recém-nascidos
}

\author{
Family member's perception on the humanized bath: japanese technique for newborns
}

\author{
Jadna Hemkemeier'; Valéria Cardoso Fermino'; Ivete Maria Ribeiro²
}

\section{RESUMO}

Objetivo: Conhecer a percepção de familiares acerca da experiência da utilização do banho humanizado, uma técnica Japonesa em recém-nascidos $(\mathrm{RN})$.

Materiais e Métodos: Trata-se de uma pesquisa do tipo exploratória, de abordagem qualitativa, conduzida pela seguinte questão norteadora: qual a percepção de familiares acerca da experiência de utilização do banho humanizado - Técnica Japonesa em recém-nascidos? Os dados dessa pesquisa foram coletados no período de maio a junho de 2011. A metodologia envolveu uma entrevista, com apenas uma pergunta, aplicada às participantes no dia em que estas realizaram o procedimento no hospital, juntamente com um roteiro de observação participante, além de outra entrevista, contendo três perguntas realizadas na visita domiciliar, dez dias após a alta hospitalar.

Resultados: Os resultados revelam que os familiares estão satisfeitos com a nova técnica de banho. Os RNs permaneceram calmos e quietos, demonstrando os benefícios do banho humanizado.

Conclusão: É imprescindível que os familiares e os profissionais da saúde aceitem novas formas de procedimentos mais humanizados para RNs. Esta nova técnica de banho possibilita que os RNs mantenham-se mais calmos, não havendo choro durante a sua execução. Entretanto, observou-se que, para a eficácia da nova técnica de banho, o RN deve ser bem enrolado no cueiro, a fim de que se sinta mais protegido.

Palavras-chave: humanização da assistência; recém-nascido; enfermagem.

\begin{abstract}
Objective: To study the perception of family members about the experience of using the humanized bath, a Japanese technique for newborns (NB).

Materials and Methods: This is an exploratory research with a qualitative approach, motivated by the following question: what is the perception of family members about the experience of using the humanized bath - Japanese technique for newborns? All data were collected between may and june of 2011. The methodology involved an interview with just one question, applied to the participants during the day they realized the procedure at the hospital, along with an observation script. We also conducted another interview, with three questions, during a home visit, ten days after participants were discharged from hospital.

Results: The results show that family members are satisfied with the new bath technique. The NB remained calm and quiet, showing the benefits of the humanized bath.

Conclusion: It is essential that family members and health professionals accept new forms of more humane procedures for NB. This new technique allows the bath to keep the newborns calmer, with no crying during their execution. However, it was observed that for the effectiveness of this new bath technique, the NB should be well wrapped in swaddling clothes, in order to feel more protected.
\end{abstract}

ABSTRACT

Keywords: assistance humanization; newborn; nursing.

${ }^{1}$ Acadêmicas de Enfermagem - Universidade do Sul de Santa Catarina - UNISUL.

${ }^{2}$ Enfermeira. Mestre em Assistência de Enfermagem pela Universidade Federal de Santa Catarina. Professora da Universidade do Sul de Santa Catarina. 


\section{INTRODUÇÃO}

A humanização é uma forma de assistir o ser humano, enfatizando a atenção à saúde individual e coletiva, desenvolvida com educação e eficiência, garantindo os direitos dos envolvidos, bem como sua promoção, proteção e recuperação ${ }^{1}$.

Percebe-se que a humanização pode ser desenvolvida de forma mais adequada quando tratamos de pacientes comunicativos, que conseguem expressar suas dores, medos e emoções. Porém, em se tratando de Neonatologia, o trabalho torna-se mais difícil, em virtude da expressão indefinida do choro do RecémNascido (RN), uma vez que quem o assiste nem sempre consegue identificar a causa do desconforto.

O momento do banho deve ser um momento prazeroso para o bebê, para que o mesmo se sinta bem. O banho mais utilizado nos dias de hoje é o banho humanizado - Técnica Usual, onde o RN é colocado despido em uma banheira ou bacia com água, para promoção da higiene. Nesta pesquisa optou-se por desenvolver outra técnica de banho, denominada banho humanizado - Técnica Japonesa, na qual o bebê é levado enrolado em uma fralda para a bacia, banheira ou balde, e somente dentro da água ele será descoberto. Neste procedimento o neonato não se sentirá inseguro e sim em um lugar semelhante ao útero materno ${ }^{2}$.

A participação ativa da mãe, do pai e da família reforça o significado do banho como um momento de interação e trocas ${ }^{2}$. O primeiro cuidado materno consiste na ligação da mãe com o bebê, com o fator adicional do contato. Um momento importante para desenvolver este contato é durante o banho, onde a criança revive momentos que lhe são familiares ${ }^{3}$.

Esta pesquisa foi embasada nas diretrizes de humanização da assistência, descritas por Feyer et al. ${ }^{2}$ e a Cartilha de Humanização do SUS ${ }^{4,5}$. A Assistência Humanizada ao RN preconiza priorizar as necessidades deste, garantindo sua evolução e crescimento, para que o RN se torne uma pessoa respeitada pela sociedade e consciente de seus direitos e deveres ${ }^{5}$.

Aperfeiçoar a técnica do banho no neonato é imprescindível para os profissionais da equipe de enfermagem, pois nos dias de hoje existem muitas contradições que requerem mais estudos nessa área. Podemos destacar equívocos que ainda requerem clareza aos familiares como exemplo o uso do sabonete, shampoo, óleos, cremes, loção e lenços umedecidos de limpeza ${ }^{6,7,8}$.

Justifica-se este estudo em virtude do banho humanizado - Técnica Japonesa não ser realizado em um hospital do sul de Santa Catarina, que é referência regional no cuidado de gestante de alto risco e apresenta grande incidência de partos. Uma segunda motivação foi conhecer a diferença de comportamento dos RNs submetidos à técnica de banho humanizado Técnica Japonesa e os submetidos ao banho humanizado - Técnica Usual. Outra motivação foi investigar a importância de realizar este novo procedimento com o neonato, a fim de minimizar as dificuldades que os familiares apresentam para oferecer conforto aos seus bebês.

Acredita-se que o conhecimento da importância de humanizar a assistência permite identificar aspectos que necessitam ser aprimorados e/ou modificados. Neste sentido, o estudo pretendeu, além de testar um novo conhecimento na área da enfermagem, contribuir com a prática da equipe de enfermagem, com a instituição, com os familiares e principalmente com o bem estar do neonato. O objetivo foi conhecer a percepção de familiares acerca da experiência de utilização do banho humanizado - Técnica Japonesa em seu recémnascido.

\section{MATERIAIS E MÉTODOS}

Esse estudo é uma pesquisa exploratória, com abordagem qualitativa. Segundo Minayo, abordagem qualitativa é aquela que segue a mesma orientação de quando se realiza uma investigação. Há, portanto, uma problematização do estudo, coleta de dados e, por fim, a análise das informações obtidas ${ }^{9}$.

O estudo foi desenvolvido em dois momentos e dois locais distintos. O primeiro momento foi realizado no setor de Alojamento Conjunto de um hospital do sul de Santa Catarina. No segundo momento, as pesquisadoras realizaram uma visita domiciliar aos familiares, mediante a sua aceitação. Foram convidados a participar do estudo cinco puérperas, adotando como 
critério de inclusão das participantes: puérperas, multíparas, com idade igual ou superior a 18 anos, que residem em municípios da região e que aceitaram e assinaram o Termo de Consentimento Livre e Esclarecido - TCLE, de forma voluntária.

O presente estudo está fundamentado nos preceitos éticos descritos na Resolução 196/96 do Conselho Nacional de Saúde ${ }^{10}$. Durante todo o estudo foi respeitado o sigilo e o anonimato dos participantes, preservando seus dados pessoais, sua privacidade, respeitando suas crenças e opiniões. A pesquisa foi aprovada pelo Comitê de Ética e Pesquisa - CEP da Universidade do Sul de Santa Catarina, com registro de número 11.108.4.04.III.

A coleta de dados foi desenvolvida em cinco momentos, no intuito de esclarecer a proposta deste estudo, a saber: 1) Escolher os sujeitos através do prontuário das puérperas; 2) Realizar contato com a puérpera selecionada e depois do aceite assinar o TCLE; 3) Orientar o banho humanizado - Técnica Japonesa; desenvolver o banho humanizado - Técnica Japonesa, demonstrando-o para a pessoa-familiar que for realizá-lo; 4) Observar como o familiar realiza a técnica e possibilitar o aperfeiçoamento da mesma, esclarecendo possíveis dúvidas e observando o comportamento do neonato durante o procedimento; 5) Realizar a visita domiciliar.

Como questão de pesquisa foi definida: Qual a percepção de familiares acerca da experiência de utilização do banho humanizado - Técnica Japonesa em seus recém-nascidos? Esta questão foi desenvolvida no momento em que o familiar realizou a técnica no hospital e durante a visita domiciliar. No momento do banho realizado pelo familiar também foi observado o comportamento do $\mathrm{RN}$, mediante um instrumento de observação participante criado para esse fim. Na visita domiciliar, as pesquisadoras questionaram o familiar sobre a comparação entre o banho humanizado - Técnica Japonesa e a técnica do banho usual realizado com os seus outros neonatos.

Os registros dos dados foram efetuados no instrumento de entrevista e no instrumento de observação participante.

Para realização da Técnica Japonesa deve-se, inicialmente, deixar o ambiente aquecido e preparar os materiais. Após o preparo, o $\mathrm{RN}$ deve ser despido, enrolado em uma fralda ou cueiro e colocado na água. Durante a execução do banho, deve-se descobrir primeiro um lado, lavar e em seguida cobri-lo novamente, repetindo o mesmo procedimento no lado oposto, para que o bebê se habitue à água. O RN será completamente despido apenas no momento de lavar a parte posterior. Para finalizar, o bebê deve ser retirado da água enrolado em um cueiro seco, permanecendo próximo de quem executa a técnica. Posteriormente, o RN é vestido. É importante ressaltar que durante a técnica, o diálogo entre quem executa o banho e o RN é fundamental, sugerindo-se inclusive o uso de cantigas ${ }^{2}$.

Os dados foram analisados conforme proposto por Minayo $^{9}$ que segue os seguintes passos: ordenação, classificação e análise final dos dados.

\section{RESULTADOS E DISCUSSÃO}

O presente capítulo refere-se à descrição dos resultados e a discussão dos dados obtidos durante a pesquisa sobre a percepção de familiares acerca da experiência de utilização do banho humanizado Técnica Japonesa em seu recém-nascido. Visando priorizar o anonimato dos participantes, utilizamos pseudônimo com nomes de cores para cada participante, são eles: Azul, Amarelo, Roxo, Verde e Vermelho.

Todas as participantes desta pesquisa são puérperas, com idade entre 20 e 33 anos, possuindo número de filhos variando entre 2 e 3 . Uma das participantes é Enfermeira, outra é Zeladora e as demais desenvolvem trabalho no lar. Quanto ao estado civil, duas entrevistadas são casadas e três vivem em união consensual. Uma possui curso superior completo, uma possui ensino médio completo, duas possuem ensino fundamental completo e uma possui ensino médio incompleto. Duas mães residem no município de Tubarão, duas no município de Capivari de Baixo e outra no município de Laguna - SC.

Experiência a respeito da utilização do banho humanizado - Técnica Japonesa 
Ao serem orientadas sobre o novo método de banho, as participantes também foram questionadas quanto a sua experiência em realizar esta técnica pela primeira vez, facultando às pesquisadoras a comparação da percepção dos familiares no primeiro contato com a técnica e após dez (10) dias de uso em domicílio. A análise dos dados revelou as seguintes categorias: percepções, expectativas, sentimentos, facilidades e dificuldades na execução da técnica.

Após dez dias de execução do Banho HumanizadoTécnica Japonesa pelo familiar em domicílio, foi realizado uma visita domiciliar, com intuito de avaliar essa experiência. Nessa fase novamente emergiram as categorias: percepções, sentimentos, facilidades e dificuldades no desenvolvimento da técnica.

\section{Percepções}

Após análise dos dados obtidos, ficou evidente que as mães gostaram da nova técnica, confirmada nos relatos a seguir:

Gostei, achei bem interessante, a técnica é bem boa [...] (Vermelho).

Eu gostei, acho que dá para fazer em casa tranquilo [...]. (Amarelo).

Interessante né, bem melhor. É impossível não dar certo [...]. (Verde).

Sabe-se que o banho é essencial para o $\mathrm{RN}$, devendo ser prazeroso tanto para ele quanto para o familiar que o executa. Permanecendo calmo e com maior tempo de sono, o RN terá benefícios em seu bem estar físico e mental, proporcionando ao familiar maior tranquilidade.

Esta nova técnica de banho permite humanizar a assistência ao recém-nascido pelo fato de promover higienização e aumentar a afetividade entre o familiar e o neonato, possibilitando maior conforto e acolhimento, principalmente quando é retirado da água e é aproximado ao peito do familiar ${ }^{11}$.

No entanto, após a realização da técnica em domicílio pode-se comparar a percepção dos familiares no primeiro contato com a técnica e após alguns dias de execução da mesma. Observa-se que eles gostaram e eliminaram quaisquer percepções insatisfatórias relacionadas com esta técnica.

Foi bom e eu gostei. (Vermelho).

Muito bom né. É bem tranquilo. (Amarelo).

É uma bênção [...] ás vezes deixava sem tomar banho para não ver eles assim, até falei para vocês no hospital isso e pensei que não fosse dar certo. (Verde).

\section{Expectativas}

Observou-se que as participantes do estudo apresentaram grande probabilidade de continuar a técnica em seus domicílios, pois há expectativas de sucesso em sua execução, como identificamos na descrição a seguir:

É boa, vou tentar fazer, acho que pode dar certo, [...] nos próximos filhos vou fazer assim [...]. (Roxo).

[...] Vou continuar em casa e acho que vai dar certo [...]. (Vermelho).

A humanização do $\mathrm{RN}$ deve caracterizar-se pela segurança técnica da atuação de quem o cuida e das condições adequadas para a realização de determinados procedimentos, aliados à suavidade no toque durante a execução de todos os cuidados prestados ${ }^{4}$. O cuidado desenvolvido pelas acadêmicas proporcionou aos familiares evidenciar reações positivas no RN. Também fez com que eles adquirissem maior segurança e confiança em dar continuidade à nova técnica.

\section{Sentimentos}

Por ser uma técnica diferente de banho, a qual os familiares não estavam habituados, percebeu-se sentimentos de medo, de satisfação e de proteção ao bebê. Observa-se que esses sentimentos impulsionam a realização desse procedimento, conforme relatos a seguir:

[...] Senti um pouco de medo. (Vermelho).

[...] É legal e eu gostei. (Azul).

[...] ele se sente mais protegido, não ta pelado. (Verde). 
No domicílio, observou-se que um familiar entrevistado, já habituado com o método usual de banho em RN, apresentou medo na execução da nova técnica. No entanto, isso não impediu a continuidade da técnica, apresentando por fim sentimentos positivos perante o procedimento. Outro relato mostra que o familiar gostou e está repassando a técnica para outras pessoas, como podemos identificar nas descrições a seguir:

[...] Legal, tenho um pouco de medo, se fosse o primeiro filho para mim seria mais fácil, porque assim eu já tenho o meu jeito de dar o banho. É bem diferente, mas é bom. (Azul).

Gostei tanto que até mostrei pra minha vizinha que ganho neném. (Roxo).

Segundo o Ministério da Saúde, a equipe responsável pela assistência ao recém-nascido deve ser habilitada para promover a aproximação, o mais precocemente possível, entre a mãe e o bebê, para fortalecer o vínculo afetivo. Essa técnica de execução do banho promove reações positivas no bebê e estes fatores facilitam a aproximação de familiares com o RN. Assim, o familiar é estimulado a realizar a assistência da maneira mais agradável possível ${ }^{4}$.

\section{Facilidades e dificuldades}

Uma das entrevistadas confirmou após conhecer a técnica do banho que, mesmo achando-a diferente, ela é fácil de ser realizada. Outra relatou que a dificuldade se deve à inexperiência, por ser um procedimento novo, segundo descrito abaixo:

\section{[...] nem é difícil, é só diferente. (Vermelho). \\ [...] No começo vai ser um pouco difícil. (Azul).}

Sabe-se que hoje em dia as pessoas têm certa resistência ao que é novo, acreditando que por ser desconhecido poderá trazer dificuldades. O que ocorre, é que os obstáculos encontrados não são rotineiros, mas facilmente resolvidos. Os meios de comunicação, inclusive na área da saúde, propagam as informações com mais facilidade, fazendo com que a população perca seus medos e favoreça as mudanças de certos cuidados, tornando-os mais humanizados.

Um procedimento novo, quando realizado mais de uma vez, acaba se tornando mais simples e de fácil execução, como se evidencia na resposta abaixo quando foi realizada a visita domiciliar para os participantes deste estudo:

Ta dando tudo certo, pensei que era mais difícil. Quando não é eu que faço é a madrinha que faz. (Roxo).

\section{Observação participante}

Durante a execução do banho realizado pelo familiar, observaram-se distintas características do $\mathrm{RN}$, de acordo com cada etapa estabelecida pelas acadêmicas pesquisadoras. São elas: quando retira a roupa, quando é colocado na água, durante a execução do banho, após a retirada da água e no momento de vestir a roupa.

Quanto às características apresentadas pelo $\mathrm{RN}$, estabeleceram-se alguns critérios para avaliação, como: calmo-quieto, quando o $\mathrm{RN}$ apresentava-se tranquilo e sem choro; choro fraco, quando se observava que o RN estava choramingando; choro forte, quando o $\mathrm{RN}$ chorava muito e sem parada.

Nas etapas de retirada e colocação das roupas, dois RNs apresentaram choro fraco, devido ao fato de estarem despidos e se sentirem desprotegidos. Além disso, estes momentos favorecem a perda de calor, pois o RN apresenta dificuldade na conservação térmica na hora da mudança de postura, na hora da retirada das roupas e pela demora na colocação de suas vestes. Uma forma de expressar que está sentindo frio é através do choro ${ }^{4}$.

Durante a execução do banho, apenas um RN apresentou choro fraco, observou-se que ele não estava bem enrolado no cueiro, como determina o Banho Humanizado - Técnica Japonesa.

No momento de retirada da água, todos os RNs apresentaram-se calmos e quietos. Isso se deve ao fato do $\mathrm{RN}$ estar próximo do familiar, podendo sentir e evitar a perda de calor. Dessa forma, os RNs não sofrem hipotermia e permanecem aconchegados ${ }^{4,11}$. 
Técnica Japonesa comparada com a técnica do banho de imersão realizado com seus outros filhos

\section{Diferenças e reações dos recém-nascidos}

Quando o RN é retirado de seu aconchego, como quando começa a ser despido para tomar banho, é estimulado, e a sua reação será o choro, pois esta é sua única forma de manifestação.

Segundo os relatos das participantes no banho humanizado - Técnica Usual, os bebês apresentavam reações como choro e agitação. No entanto, na nova técnica de banho humanizado - Técnica Japonesa, as participantes relataram que os bebês estão ficando mais calmos, dormindo melhor e não estão chorando tanto, como se nota a seguir:

[...] ele não chora para tomar banho, a menina era diferente. Fica calminho, [...]. (Vermelho).

O banho dos outros era mais agitado, esse fica mais calmo. Fica calmo até na hora de colocar a roupa. (Amarelo).

Não tem nem comparação, como eu já disse ou outros choravam muito e esse parece que sente prazer. (Verde).

Minha filha ta dormindo melhor e não ta chorando tanto, as outras choravam muito. (Azul).

\section{Importância}

Para os familiares é importante saber que os bebês estão protegidos. Garantida a proteção, os familiares se sentirão mais seguros, facilitando a execução e o desenvolvimento de determinadas tarefas. Inclusive o bebê, quando se sente mais protegido, tenderá a ficar calmo e quieto.

É importante. Porque ela ta bem enroladinha daí ela não chora. (Roxo).

\section{Benefícios, vantagens e desvantagens}

Nesta categoria pode-se observar que as participantes relataram que o bebê gostou e facilitou a proteção contra o frio. Outra participante refere que ainda considera a técnica japonesa difícil, pois já estava habituada com a outra técnica de banho.
Ele gosta [...] até protege do frio. (Vermelho).

[...] não sente tanto frio! [...]. (Roxo).

[...] Como já falei, to achando um pouco difícil, pois já tinha o meu jeito. (Azul).

Ao final da visita domiciliar as acadêmicas deixaram um espaço aberto para que as participantes pudessem dar sugestões e contribuições para a pesquisa, assistência e utilização da técnica no hospital.

As puérparas comentaram que a nova técnica foi boa, devendo ser repassada para outras mães e possivelmente implantar no hospital, para que todos tenham acesso. Fato este que proporciona satisfação com o trabalho realizado e a perspectiva de implantação desta técnica no hospital referido.

Mostrar para as mães no hospital. (Vermelho).

Vale a pena continuar, é benéfico. (Amarelo).

Que seja divulgado e repassado para as próximas mães. (Verde).

Bem boa! Deveria ter com todas as mães daqui. (Roxo).

Percebe-se que a humanização, quando colocada em prática, é facilmente evidenciada. Infelizmente ela não é executada em todos os lugares e com todos os indivíduos, pelo fato de exigir maior tempo e disponibilidade do profissional, especialmente quanto se trata de pessoas adultas. No entanto, nos procedimentos com RNs, é necessário encontrar formas de humanizar a assistência, pois o RN não dialoga com a equipe e com os familiares. Assim, é importante que a equipe multiprofissional seja capacitada, para que possa rever determinadas técnicas e torná-las ainda mais humanizadas, trazendo benefícios para quem as recebe.

\section{CONSIDERAÇÕES FINAIS}

O referencial teórico utilizado para construção desta pesquisa facilitou o desenvolvimento da técnica, pois este destaca e prioriza a humanização da assistência, especialmente no banho do neonato, permitindo assim que a enfermagem fundamente cientificamente suas 
ações. Esse estudo preocupou-se em desenvolver o cuidado humanizado durante o processo de coleta de dados, conforme propõe a Cartilha de Humanização do SUS.

A partir da análise dos dados, observou-se que seria mais fácil a execução da técnica pelos familiares em seus domicílios se fossem primíparas, pois não teriam experiências anteriores com outro tipo de banho. Entretanto, o desenvolvimento deste estudo com multíparas foi positivo, pois a maioria das participantes puderam comparar as duas técnicas de banho mencionadas no trabalho e verificar os benefícios para o neonato.

Conclui-se também que o RN deve ser bem enrolado, para não se sentir solto e desprotegido. Quando retirado da água, o mesmo deve ficar bem perto de quem está executando o banho, para que recupere a temperatura corpórea adequada e de forma rápida. Os momentos utilizados para o desenvolvimento da nova técnica facilitaram a compreensão das participantes da pesquisa sobre o procedimento, pois elas puderam primeiro assistir a realização do banho oferecido pelas acadêmicas e, no outro dia, quando elas mesmas realizaram o banho, puderam esclarecer suas dúvidas. Isso facilitou a intervenção das acadêmicas quando evidenciaram algumas dificuldades.

Sendo assim, este estudo permite inferir que essa nova técnica de banho torna o momento mais humanizado e afetivo, diminuindo sensivelmente os episódios de choro durante o banho. Frente a essa realidade, ousa-se deixar como sugestão que a instituição hospitalar ofereça o banho humanizado Técnica Japonesa às futuras mães e proporcione novos treinamentos de humanização em $\mathrm{RN}$ à equipe multiprofissional.

Existe necessidade de outras pesquisas nessa área, pois a única dificuldade encontrada pelas pesquisadoras foi à carência de bibliografias para maior fundamentação teórica. Considera-se o estudo não conclusivo, podendo ser refeito em outras instituições, com números maiores de participantes, a fim de obter dados mais expressivos.

\section{REFERÊNCIAS}

1. Costa WS. Humanização, relacionamento interpessoal e ética. Cad Pesqui Adm. 2003 Jan;11(1):17-21.

2. Feyer ISS, Silva J, Koettker JG, Calvette MF, Burigo RA, Collaço VS. O florescer da vida: parto domiciliar planejado. Florianópolis: Lagoa; 2009.

3. Ribble MA. Os direitos da criança: as necessidades psicológicas iniciais e sua satisfação. $2^{\mathrm{a}}$ ed. São Paulo: Imago; 1975.

4. Brasil. Secretaria de Políticas de Saúde. Atenção humanizada ao recém-nascido de baixo peso: método canguru: manual do curso. Brasília: Ministério da Saúde; 2002.

5. Brasil. Secretaria de Atenção à Saúde. Atenção humanizada ao recém-nascido de baixo peso: método canguru. Brasília: Ministério da Saúde; 2009.

6. Fernandes JD, Machado MCR, Oliveira ZNP. Prevenção e cuidados com a pele da criança e do recém-nascido. An. Bras. Dermatol. 2011 Jan./Feb; 86(1): 102-10. [capturado em 2011 dez. 28]. Disponível em: http://dx.doi.org/10.1590/S0365-05962011000100014.

7. MacDonald MMK, Mullertt MD, Seshia MMK. Avery, neonatologia: fisiopatologia e tratamento do recémnascido. $6^{\mathrm{a}}$ ed. Rio de Janeiro: Guanabara Koogan; 2007.

8. Tamez RN, Silva MJP. Enfermagem na UTI Neonatal: assistência ao recém-nascido de alto risco. $2^{2}$ ed. Rio de Janeiro: Guanabara Koogan; 2002.

9. Minayo MCS. O desafio do conhecimento: pesquisa qualitativa em saúde. 8ª ed. São Paulo: Hucitec; 2004

10. Brasil. Conselho Nacional de Saúde. Resolução $n^{0} 196$, de 10 de outubro de 1996: diretrizes e normas regulamentadoras de pesquisa envolvendo seres humanos. Brasília: CNS; 1996.

11. Collaço VS, Cordeiro MG, Ferreira GJ, Henckemaier L, Koettker JG, Santos EKA. Técnicas de banho tradicional e humanizado Japonês: reações do recém-nascido. In: VII Congresso Brasileiro de Enfermagem Obstétrica e Neonatal VII COBEON- Congresso Internacional de Enfermagem Obstétrica e Neonatal I CIEON - V Fórun Nacional de Políticas de Atuação de Enfermeiros e Obstetrizes na Assistência à Saúde da Mulher. Belo Horizonte: ABENFO; 2011. p. 3619-3620.

\section{Endereço para correspondência:}

Ivete Maria Ribeiro

Av. José Acácio Moreira 59, apt 102-C

Tubarão/SC - CEP 88704-000

Telefone: +554836213287

E-mail: ivete.ribeiro@unisul.br 